\title{
DESAFIOS À RESERVA DE VAGAS PARA NEGROS EM CONCURSOS PÚBLICOS PARA DOCENTES EM INSTITUIÇÕES FEDERAIS DE ENSINO
}

\author{
Rosane Rosa Dias Fernandes ${ }^{1}$ \\ Victor Silva SANTOS ${ }^{2}$ \\ Alexandre JaCOB ${ }^{3}$ \\ RANY Rosa Dias 4
}

\begin{abstract}
RESUMO: O artigo trata de analisar a aplicação da Lei no 12.990/2014, que reserva $20 \%$ das vagas de concursos públicos federais para candidatos negros, no âmbito dos concursos para docentes, nas duas instituições federais de ensino do Espírito Santo: Universidade Federal do Espírito Santo (Ufes) e Instituto Federal de Educação, Ciência e Tecnologia do Espírito Santo (Ifes). Apresenta conceitos importantes para o debate sobre as desigualdades raciais, como políticas públicas, ações afirmativas, racismo estrutural e institucional. Analisa 189 editais de concursos para docentes, das instituições federais de ensino do Espírito Santo, do período de 2014 a 2020. Ao final do estudo, conclui que as instituições pesquisadas não aplicam a reserva de vagas para negros conforme indica a Lei $\mathrm{n}^{\circ}$ 12.990/2014.
\end{abstract}

Palavras-chave: Lei $n^{\circ}$ 12.990/2014. Racismo Institucional. Ações Afirmativas. Desigualdade Racial. Concurso Público Docente.

\section{CHALLENGES TO THE RESERVATION OF POSITIONS FOR BLACK PEOPLE AS PUBLIC TEACHERS IN FEDERAL EDUCATION INSTITUTIONS}

ABSTRACT: The article analyzes the application of Law No. 12,990/2014, which reserves $20 \%$ of federal public positions for black candidates, among the teachers, in the two federal teaching institutions in Espírito Santo: Universidade Federal do Espírito Santo (Ufes) and Instituto Federal de Educação, Ciência e Tecnologia do Espírito Santo (Ifes). It presents important concepts for the debate on racial inequalities, such as public policies, affirmative actions, structural and institutional racism. It analyzes 189 public convocatory for teachers, from federal educational institutions in Espírito Santo, of the period 2014 to 2020. At the end of the study, it concludes that the institutions surveyed do not apply the reservation of vacancies for black peoples, as indicated by Law No. 12.990/2014.

Keywords: Law No. 12,990/2014. Institutional Racism. Affirmative Actions. Racial Inequality. Positions for Public Teachers.

\footnotetext{
1.Instituto Federal de Educação, Ciência e Tecnologia do Espírito Santo - Colatina (ES), Brasil. E-mail: rosanerosadias@gmail.com 2.Instituto Federal de Educação, Ciência e Tecnologia do Espírito Santo - Colatina (ES), Brasil. E-mail: victor.domus@gmail.com 3.Faculdade Alfa Unipac Aimorés - Aimorés (MG), Brasil. E-mail: alexandre.jacob10@gmail.com 4. Instituto Federal de Educação, Ciência e Tecnologia do Espírito Santo - Itapina (ES), Brasil. E-mail: ranyrosadias@gmail.com Editor de Seção: Salomão Barros Ximenes Editores convidados: Nilma Lino Gomes, José Eustáquio Brito e Paulo Vinicius Baptista da Silva
} 


\section{DESAFÍOS PARA LA RESERVA DE PLAZAS PARA NEGROS EN OPOSICIONES PÚBLICAS PARA MAESTROS EN INSTITUCIONES DE EDUCACIÓN FEDERAL}

RESUMEN: El artículo analiza la aplicación de la Ley n 12.990/2014, que reserva $20 \%$ de las plazas de las oposiciones públicas federales para candidatos negros, en el ámbito docente, en las dos instituciones docentes federales de Espírito Santo: Universidade Federal do Espírito Santo (Ufes) e Instituto Federal de Educação, Ciência e Tecnologia do Espírito Santo (Ifes). Presenta conceptos importantes para el debate sobre las desigualdades raciales, como políticas públicas, acciones afirmativas, racismo estructural e institucional. Analiza 189 convocatorias para oposiciones públicas para docentes, de instituciones educativas federales en Espírito Santo, del período de 2014 hasta 2020. Al final del estudio, concluye que las instituciones analizadas no aplican la reserva de plazas para negros, como indica la Ley $n^{\circ} 12.990 / 2014$.

Palabras-clave: Ley no 12.990/2014. Racismo Institucional. Acciones Afirmativas. Desigualdad Racial. Oposiciones Públicas para Maestros.

\section{Introdução}

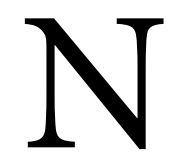

a luta contra a desigualdade racial no Brasil, o início do século XX foi marcado pela ampliação do movimento negro, que passou a atuar nos campos social, cultural e político, com ações que impactam de forma mais contundente a sociedade brasileira, como exemplo a conquista da Lei $n^{\circ} 10.639 / 2003$, voltada para a valorização da história e cultura afro-brasileira na educação.

Somado a isso, tem-se também o comprometimento do Brasil com o programa de ação construído na Conferência Mundial de Combate ao Racismo, Discriminação Racial, Xenofobia e Intolerância Correlata, ocorrida em Durban, África do Sul, em 2001, que, entre outros tópicos, propunha combater as vulnerabilidades de grupos específicos, entre eles a população negra, que no Brasil é composta dos autodeclarados pretos e pardos, conforme estabelecido pelo Instituto Brasileiro de Geografia e Estatística (IBGE, 2018).

Todavia, reduzir a desigualdade entre negros e brancos brasileiros é uma tarefa complexa que perpassa por questões históricas, sociais e econômicas. De acordo com dados da Pesquisa Nacional por Amostra de Domicílios (PNAD) 2018, 56,2\% dos brasileiros se declararam negros (IBGE, 2018). As estatísticas produzidas pelo IBGE demonstram que o Brasil está longe de ser uma democracia racial. Os pretos e pardos sofrem com salários menores e maiores taxas de desemprego, entre outros índices socioeconômicos, quando comparados com a população branca.

De acordo com Sílvio Almeida (2020), os resultados dessas pesquisas e suas consequências negativas advêm da discriminação sistemática, processual e histórica das minorias brasileiras, que acabam por criar uma estratificação social que se reverte em inúmeras desvantagens políticas e econômicas aos grupos minoritários, vivenciadas na forma de pobreza, salários mais baixos, menor acesso aos sistemas de saúde e educação, maiores chances de encarceramento e morte. Complementarmente a essa opinião, para Otair Fernandes (2018), tal situação deriva do longo período de colonização europeia e estruturou-se sobre o racismo institucional.

Para romper essa questão, nos últimos anos, tem-se visto a adoção de políticas públicas de diferentes naturezas propostas pelos governos que tentam equalizar as condições de vida da população. "É preciso pensar em políticas de afirmação do negro. Políticas de valorização daqueles que foram marginalizados e excluídos” (Fernandes, 2018, p. 15). Todavia, apesar dos esforços, o abismo racial ainda se faz presente. 
Uma importante iniciativa de valorização do negro e fruto da luta antirracista do movimento negro do Brasil ocorreu com a aprovação do Estatuto da Igualdade Racial, na forma da Lei no 12.288/2010, que prevê a adoção de programas de ação afirmativa destinados ao enfrentamento das desigualdades étnicas em relação a vários setores, entre eles a educação e o trabalho.

Outra iniciativa mais conhecida é a Lei $\mathrm{n}^{\circ} 12.711 / 2012$, que reserva no mínimo 50\% das vagas para ingresso nas universidades federais e nas instituições federais de ensino técnico de nível médio para estudantes que tenham cursado integralmente o ensino médio em escolas públicas. O desdobramento positivo dessa ação afirmativa resultou no aumento da presença de estudantes negros nas universidades, que chegou a 50,3\% em 2018 (IBGE, 2018).

Contudo, quando se fala de docentes, a inclusão dá-se de forma lenta. Nas universidades públicas os professores negros ainda são minoria. De acordo com o Censo do Ensino Superior do Instituto Nacional de Estudos e Pesquisas Educacionais Anísio Teixeira (Inep, 2019), o número de docentes negros subiu de 11,7 para 15,8\% entre 2014 e 2019. Mesmo pequeno, esse aumento deve-se, em parte, à aprovação da Lei $\mathrm{n}^{\circ} 12.990$, de 9 de junho de 2014, que reserva aos negros $20 \%$ das vagas nos concursos para provimento de cargos efetivos e empregos públicos no âmbito da administração pública federal. Diante dessa realidade, surge o seguinte questionamento: como se dá a aplicação da Lei no 12.990/2014 nos concursos públicos para docentes nas instituições federais de ensino do Espírito Santo?

Sendo assim, este estudo teve como objetivo geral analisar a aplicação da Lei no 12.990/2014, no âmbito dos concursos públicos para docentes, nas instituições federais de ensino do Espírito Santo. Para o seu atingimento, foi necessário analisar o Estatuto da Igualdade Racial, bem como a Lei no 12.990/2014; mapear os editais para provimento de vagas para docentes das instituições federais de ensino do Espírito Santo, com marco temporal de 2014 a 2020; e verificar como se dá a aplicação da Lei no 12.990/2014 nas instituições federais de ensino do referido estado.

Para alcance do objetivo e resposta à problemática, a pesquisa foi baseada em autores como Luciana de Barros Jaccoud e Nathalie Beghin (2002), que tratam da desigualdade racial brasileira; Jurema Werneck (2013), para a temática do racismo institucional; e Sílvio Luiz de Almeida (2019), para a questão do racismo estrutural. Somado a isso, adotam-se também como referenciais o Estatuto da Igualdade Racial (Brasil, 2010), a própria Lei no 12.990 (Brasil, 2014), entre outros.

\section{Racismo, Racismo Estrutural e Racismo Institucional}

De maneira enfática, Carlos Moore (2007) lembra que o início e o desenvolvimento do racismo se devem à luta pela posse e preservação dos recursos vitais da sociedade. No passado esses recursos eram formados por terra, força de trabalho dos escravos, especiarias, riquezas do meio ambiente. Hoje, dão-se pelo acesso a "educação, serviços públicos, serviços sociais, poder político, capital de financiamento, oportunidades de emprego, estruturas de lazer, e até ao direito de ser tratado equitativamente pelos tribunais de justiça e as forças incumbidas da manutenção da paz" (Moore, 2007, p. 284). O racismo impede o acesso a esses direitos, limitando vantagens e benefícios, com base no fenótipo.

A Declaração de Durban, produzida em 2001, na África do Sul, durante a III Conferência Mundial de Combate ao Racismo, Discriminação Racial, Xenofobia e Intolerância Correlata, demonstrou preocupação com as estruturas de instituições políticas, que muitas vezes ainda constituem fator de discriminação (ONU, 2001). O racismo foi reconhecido como ameaça para a paz mundial, e medidas públicas para a sua eliminação foram cobradas dos Estados. 
A declaração também reconheceu que a desigualdade ocorre por causa da promoção e reprodução do racismo, da discriminação racial, da xenofobia e da intolerância correlata:

Reconhecemos que, em muitas partes do mundo, africanos e afrodescendentes enfrentam barreiras como resultado de preconceitos e discriminações sociais predominantes em instituições públicas e privadas, e expressamos nosso compromisso em trabalhar pela erradicação de todas as formas de racismo, discriminação racial, xenofobia e intolerância correlata enfrentadas pelos africanos e afrodescendentes (ONU, 2001, p. 11).

Passados 20 anos da conferência, ainda estamos na luta pela erradicação de todas as formas de racismo, dificultada muitas vezes pela persistente ideia da democracia racial brasileira.

Construiu-se, a partir da mestiçagem, o mito da democracia racial, que se mantém até agora, porque qual a leitura que se faz do Brasil? Um país mestiço, que não tem negro, não tem índio, não tem branco, todo mundo é mestiço. Quem vai discriminar quem? Com isso você escamoteia os problemas da sociedade, você nega as desigualdades, você nega a discriminação racial (Munanga, 2017, p. 41-42).

Para a pesquisadora Nilma Lino Gomes (2005), a lógica do mito da democracia racial pressupõe que todas as raças e/ou etnias brasileiras estão em pé de igualdade sociorracial e que tiveram as mesmas oportunidades desde o início da formação do Brasil. Desse modo, a culpa pela desigualdade seria a incapacidade dos próprios grupos raciais, em desvantagem, e não o racismo, que se entrelaça na dinâmica da sociedade brasileira.

Afinal, o que é racismo? De acordo com Moore (2007), racismo é uma dinâmica construída histórica e fundamentalmente antinegra, atemporal, universal e transversal. Da mesma forma, Gomes (2005) associa o racismo ao ódio em relação às pessoas que possuem um pertencimento racial identificado pela cor da pele e/ou pelo tipo de cabelo.

Igualmente, para Werneck (2013, p. 11), racismo é um fenômeno "que penetra e participa da cultura, da política e da ética”. Enraizado no sistema, ele vale-se de instrumentos em favor de seus interesses e necessidades de continuidade, mantendo e perpetuando privilégios e hegemonias.

Em Sílvio Almeida (2019), vamos encontrar o acréscimo do termo raça ao definir o racismo como forma discriminatória sistemática que "se manifesta por meio de práticas conscientes ou inconscientes que culminam em desvantagens ou privilégios para indivíduos, a depender do grupo racial ao qual pertençam" (Almeida, 2019, p. 22).

Complementarmente a essas definições, o autor traz três concepções de racismo: individualista, institucional e estrutural. O racismo individualista consiste em uma anormalidade ética ou psicológica individual ou coletiva, atribuída a grupos isolados. Seu combate dar-se-ia no campo jurídico, com sanções civis ou penais, entretanto faz-se um alerta duplo: "Sob este ângulo, não haveria sociedades ou instituições racistas, mas indivíduos racistas, que agem isoladamente ou em grupo" (Almeida, 2019, p. 25). Também, ao limitarmos o racismo a aspectos comportamentais, não consideramos que as maiores fatalidades ocasionadas pelo racismo foram feitas por homens de bem, apoiados por políticos e religiosos (Almeida, 2019).

Na perspectiva institucional, racismo é o "resultado do funcionamento das instituições, que passam a atuar em uma dinâmica que confere, ainda que indiretamente, desvantagens e privilégios com base na raça" (Almeida, 2019, p. 26). O autor esclarece que as regras institucionais acabam por moldar o comportamento humano. Dessa forma, como as instituições carregam os conflitos da sociedade, os conflitos raciais também são parte das instituições. 
Na visão de Werneck (2013), o racismo institucional, também chamado de sistêmico, tem as funções de induzir, manter e condicionar a organização estatal, suas ações, instituições e políticas, atuando ainda nas instituições privadas, produzindo e reproduzindo a hierarquia racial, por consequência.

O racismo institucional atua como instrumento de exclusão de grupos racialmente subordinados, gerando e legitimando ações excludentes e garantindo a manutenção do racismo e o grupo hegemônico no poder.

Na concepção estrutural, Almeida (2019, p. 31) utiliza a seguinte argumentação: "As instituições são racistas porque a sociedade é racista”. O racismo não foi criado pela instituição, mas é representado por ela, ao reproduzir práticas sociais violentas e/ou microagressões, como piadas, silenciamento, isolamento etc. $\mathrm{O}$ autor destaca que o racismo não se limita à representatividade. Ou seja, não basta ter pessoas negras em espaços de poder, pois isso não significa que a instituição deixará de ser racista. Enfim, como Almeida (2019) deixa claro, o racismo deriva da estrutura social da sociedade.

\section{Políticas Públicas para Promoção Racial e Ações Afirmativas}

A segunda metade da década de 1990 foi marcada por uma aproximação entre o movimento negro e o Estado brasileiro, que passou a ser cobrado não apenas pelo combate à discriminação racial e ao racismo, mas também na proposição de ações positivas para a promoção da igualdade racial.

Importantes iniciativas foram tomadas, como a criação da Secretaria de Políticas de Promoção da Igualdade Racial (Seppir), da Presidência da República, o Conselho Nacional de Promoção da Igualdade Racial (CNPIR), além da Política Nacional de Promoção da Igualdade Racial (PNPIR) e do Plano Nacional de Promoção da Igualdade Racial (Planapir).

Em meados de 2003, a Universidade do Estado do Rio de Janeiro (UERJ) abriu vagas para alunos cotistas sob o critério étnico-racial. Em seguida, no ano de 2004, a Universidade de Brasília (UnB) também aderiu ao sistema de cotas, e só em 2007 se iniciou a elaboração do Programa de Apoio a Planos de Reestruturação e Expansão das Universidades Federais (Reuni), que ampliou e elevou o debate sobre as cotas raciais por meio da criação de conselhos universitários.

Outra importante conquista do movimento negro foi a criação da Lei no 12.288 , de 20 de julho de 2010, que instituiu o Estatuto da Igualdade Racial:

Art. $1^{\circ}$ Esta lei institui o Estatuto da Igualdade Racial, destinado a garantir à população negra a efetivação da igualdade de oportunidades, a defesa dos direitos étnicos individuais, coletivos e difusos e o combate à discriminação e às demais formas de intolerância étnica (Brasil, 2010, p. 15).

Para efeito do Estatuto da Igualdade Racial, em seu parágrafo $1^{\circ}$, tem-se as seguintes definições:

V - Políticas públicas: as ações, iniciativas e programas adotados pelo Estado no cumprimento de suas atribuições institucionais;

VI - Ações afirmativas: os programas e medidas especiais adotados pelo Estado e pela iniciativa privada para a correção das desigualdades raciais e para a promoção da igualdade de oportunidades (Brasil, 2010, p. 16).

Derivadas das políticas públicas, as ações afirmativas são medidas temporárias que estipulam um tratamento diferenciado visando reverter um quadro histórico de discriminação e exclusão (Jaccoud e Beghin, 
2002). Para Jaccoud e Beghin (2002), as ações afirmativas não combatem o ato discriminatório, mas sim o resultado da discriminação, ou seja, as desigualdades raciais no Brasil.

Em teoria, a política de reserva de vagas tende a diminuir o problema da desigualdade racial, ao "corrigir os efeitos presentes da discriminação praticada no passado, concretizando o ideal de efetiva igualdade de acesso a bens fundamentais e direitos de cidadania plena" (Silva, 2017, p. 10). Ela busca, por meio do tratamento desigual, enfrentar a desigualdade injustificada, arbitrária. Não se trata de desvalorizar o princípio do mérito, mas sim de sua reafirmação (Jaccoud e Beghin, 2002, p. 51).

Ao basear-se no princípio de que a promoção da igualdade é função do Estado, as ações afirmativas são uma forma de expressão do princípio da igualdade, cuja função é "restituir a igualdade de oportunidades entre os diferentes grupos raciais, promovendo um tratamento diferenciado e preferencial àqueles historicamente marginalizados" (Jaccoud e Beghin, 2002, p. 51).

Segundo o Estatuto da Igualdade Racial, a igualdade de oportunidades deve estar presente na vida econômica, social, política e cultural do país, e sua promoção se dará por meio da inclusão nas políticas públicas, tanto no desenvolvimento econômico quanto no social e na implementação de programas de ações afirmativas.

Nesse contexto, na área da educação, podemos citar algumas políticas públicas adotadas pelo Estado para a promoção da igualdade racial: a Lei no $10.639 / 2003$, que incluiu no currículo oficial da rede de ensino a obrigatoriedade da temática história e cultura afro-brasileira; o Programa Universidade para Todos (ProUni), que estabelece parte das bolsas de estudos para estudantes negros e indígenas; a introdução do recorte racial no censo escolar a partir de 2005; a Lei ${ }^{\circ} 12.711 / 2012$, a chamada Lei de Cotas, que obrigou universidades, institutos e centros federais a reservarem metade das vagas oferecidas em seus processos seletivos para candidatos cotistas e, em cada categoria de renda, vagas reservadas para pretos, pardos, índios e pessoas com deficiência; e a Lei no 12.990/2014, que reserva vagas em concursos públicos federais para negros.

\section{A Lei no $12.990 / 2014$}

Apesar da implementação de cotas raciais de forma autônoma por parte de algumas universidades federais a partir de 2003, o reflexo no mercado de trabalho não foi significativo. A ausência do negro em cargos de gestão e importância dentro das empresas e principalmente no serviço público trouxe as informações necessárias de que a ação afirmativa para o negro precisava ser ajustada visando à inserção no mercado de trabalho.

Em novembro de 2013, ao observar o gargalo entre a universidade e o mercado de trabalho da população negra, foi proposta pelo Executivo a Lei no 12.990/2014, que obteve no Congresso Nacional rápida tramitação. Essa lei representa uma etapa subsequente à adoção da reserva de vagas da Lei $\mathrm{n}^{\circ} 12.711 / 2012$, a Lei de Cotas, tornando-se imprescindível a compreensão de que estudantes pretos e pardos nas universidades públicas brasileiras não estarão no mercado de trabalho sem a ferramenta que complementará a tão sonhada ação de reparação, como tratava Abdias do Nascimento (2006).

A Lei $n^{\circ} 12.990 / 2014$, de 9 de junho de 2014, reserva aos negros o percentual fixo de $20 \%$ das vagas oferecidas nos concursos públicos. Podem concorrer às vagas de cota racial todos os candidatos que se autodeclararem negros, ou seja, pretos ou pardos, de acordo com os critérios do IBGE:

Art. $1^{\circ}$ Ficam reservadas aos negros 20\% (vinte por cento) das vagas oferecidas nos concursos públicos para provimento de cargos efetivos e empregos públicos no âmbito da administração pública federal, das autarquias, das fundações públicas, das empresas públicas e das sociedades de economia mista controladas pela União, na forma desta Lei (Brasil, 2014). 
Há que se destacar que, apesar de um avanço na luta do movimento negro e na pauta da igualdade racial, a lei só é aplicável no âmbito da administração pública federal, deixando de fora estados e municípios. A adoção de reserva de vagas nos concursos públicos não apenas vai ao encontro da determinação do artigo 39, do Estatuto da Igualdade Racial (Lei 12.288/2010), mas a cumpre:

Art. 39 O poder público promoverá ações que assegurem a igualdade de oportunidades no mercado de trabalho para a população negra, inclusive mediante a implementação de medidas visando à promoção da igualdade nas contratações do setor público e o incentivo à adoção de medidas similares nas empresas e organizações privadas (Brasil, 2014).

É possível notar que o objetivo da reserva de vagas é equilibrar o descompasso no percentual de servidores públicos federais pretos e pardos ao percentual de toda a população brasileira, tornando-se um passo importante para a efetivação da igualdade de oportunidades entre as raças, entretanto sua aplicação somente ocorrerá se o número de vagas disponibilizadas em concurso público for igual ou superior a três:

$\$ 1^{\circ} \mathrm{A}$ reserva de vagas será aplicada sempre que o número de vagas oferecidas no concurso público for igual ou superior a 3 (três).

$\$ 2^{\circ} \mathrm{Na}$ hipótese de quantitativo fracionado para o número de vagas reservadas a candidatos negros, esse será aumentado para o primeiro número inteiro subsequente, em caso de fração igual ou maior que 0,5 (cinco décimos), ou diminuído para número inteiro imediatamente inferior, em caso de fração menor que 0,5 (cinco décimos) (Brasil, 2014).

Outro ponto a se destacar na Lei no $12.990 / 2014$ é que os autodeclarados negros podem disputar tanto as vagas destinadas às cotas raciais quanto à ampla concorrência. Ainda, caso o candidato seja aprovado na ampla concorrência, não será computado nas vagas reservadas, liberando com isso mais uma possibilidade para preenchimento dos autodeclarados pretos ou pardos.

Art. $3^{\circ}$ Os candidatos negros concorrerão concomitantemente às vagas reservadas e às vagas destinadas à ampla concorrência, de acordo com a sua classificação no concurso.

$\$ 1^{\circ}$ Os candidatos negros aprovados dentro do número de vagas oferecido para ampla concorrência não serão computados para efeito do preenchimento das vagas reservadas.

$\$ 2^{\circ}$ Em caso de desistência de candidato negro aprovado em vaga reservada, a vaga será preenchida pelo candidato negro posteriormente classificado.

$\$ 3^{\circ} \mathrm{Na}$ hipótese de não haver número de candidatos negros aprovados suficiente para ocupar as vagas reservadas, as vagas remanescentes serão revertidas para a ampla concorrência e serão preenchidas pelos demais candidatos aprovados, observada a ordem de classificação (Brasil, 2014).

O acompanhamento e a avaliação anual da aplicação da Lei no 12.990/2014 são executados pelo órgão responsável pela política de promoção da igualdade étnica, de que trata o Estatuto da Igualdade Racial, conforme indica a própria lei: 
Art. $5^{\circ} \mathrm{O}$ órgão responsável pela política de promoção da igualdade étnica de que trata o $\$ 1^{\circ}$ do art. 49 da Lei ${ }^{\circ}$ 12.288, de 20 de julho de 2010, será responsável pelo acompanhamento e avaliação anual do disposto nesta Lei, nos moldes previstos no art. 59 da Lei no 12.288 , de 20 de julho de 2010 (Brasil, 2014).

Essa recomendação também é tratada no Estatuto da Igualdade Racial:

Art. 49 [...].

$\$ 1^{\circ}$ A elaboração, implementação, coordenação, avaliação e acompanhamento da PNPIR, bem como a organização, articulação e coordenação do Sinapir, serão efetivados pelo órgão responsável pela política de promoção da igualdade étnica em âmbito nacional.

$[\ldots]$

Art. 59 O Poder Executivo federal criará instrumentos para aferir a eficácia social das medidas previstas nesta Lei e efetuará seu monitoramento constante, com a emissão e a divulgação de relatórios periódicos, inclusive pela rede mundial de computadores (Brasil, 2010).

Em 2021, a Secretaria Nacional de Políticas de Promoção da Igualdade Racial (SNPIR), que faz parte do organograma do Ministério da Mulher, da Família e dos Direitos Humanos, é a responsável pela produção e pela divulgação de relatórios sobre a aplicação da Lei no 12.990/2014. Em consulta à página do referido ministério, no tema População Negra e Povos e Comunidades Tradicionais, realizada no dia 11 de abril de 2021, não encontramos nenhum relatório sobre o acompanhamento da aplicação da Lei. Todavia, consta como informação que o Sistema de Monitoramento de Políticas Étnico-Raciais (Simope) está em construção.

Foi a fragilidade da fiscalização um dos motivos indicados na tese de doutorado de Vanessa Cristina Lourenço Casotti Ferreira da Palma, realizada em 2019, que impediam a efetividade da Lei no 12.990/2014 em concursos públicos para docentes de universidades federais do Brasil. O trabalho analisou as cotas para negros em concursos públicos para os cargos de docentes nas universidades federais brasileiras, de 2014 a 2017. Nesse período, de acordo com a pesquisa, a Universidade Federal do Espírito Santo (Ufes) ofertou 31 vagas, sendo seis reservadas para as cotas (Palma, 2019).

Em 2019, Luiz Mello e Ubiratan Pereira de Resende verificaram a aplicação da Lei no 12.990/2014 em mais de três mil editais de concursos para docentes, de 63 universidades federais no Brasil. $O$ trabalho concluiu que em mais de 15 mil vagas ofertadas em um período de três anos e meio o percentual de vagas destinadas aos negros não passava de 5\% (Mello e Resende, 2019).

\section{Percurso Metodológico}

O método adotado para o percurso metodológico da pesquisa foi o qualitativo, com a finalidade de analisar a aplicação da Lei no 12.990/2014, no âmbito dos concursos públicos para docentes, nas instituições federais de ensino do Espírito Santo: a Ufes e o Instituto Federal de Educação, Ciência e Tecnologia do Espírito Santo (Ifes). 
Para obtenção dos dados da pesquisa bibliográfica, foram analisados os editais de concursos públicos para docentes de ambas as instituições, disponíveis em seus sites, no período de 2014 a 2020 . O critério para análise baseou-se na relação entre a quantidade de vagas constantes do edital e a aplicação da reserva de 20\%, nos termos da Lei no $12.990 / 2014$.

Em relação à contabilização do quantitativo de vagas das instituições, optou-se por agregar os concursos por ano e não separá-los por campi. Assim, a análise concentrou-se no total de vagas ofertadas em determinado ano pela instituição pesquisada.

\section{Sobre as Instituições Federais de Ensino do Espírito Santo}

Em 5 de maio de 2021, a Ufes completou 67 anos de história na educação capixaba. Atualmente possui quatro campi universitários, localizados nos bairros de Goiabeiras e Maruípe, na cidade de Vitória; e nos municípios de Alegre, no sul do estado; e São Mateus, no norte capixaba.

No ano de 2021 conta com 103 cursos de graduação presenciais, com o total de 5.004 vagas anuais. Possui 62 cursos de mestrado e 32 de doutorado. O quadro de servidores efetivos é composto de 1.780 docentes e 1.928 técnicos administrativos (Ufes, 2021).

Já a história do Ifes se iniciou em 1909, com a criação da Escola de Aprendizes Artífices do Espírito Santo. Com a Lei no 11.892, de 29 de dezembro de 2008, que instituiu a Rede Federal de Educação Profissional, Científica e Tecnológica, houve a união de quatro instituições federais de educação do Espírito Santo: o Centro Federal de Educação Tecnológica do Espírito Santo, a Escola Agrotécnica Federal de Alegre, a Escola Agrotécnica Federal de Colatina e a Escola Agrotécnica Federal de Santa Teresa, resultando no Ifes.

Com 22 campi em funcionamento em 2021, incluindo o Centro de Referência em Formação e Educação a Distância (Cefor), o Ifes está presente em todas as microrregiões do Espírito Santo. O instituto possui ainda 49 polos de educação a distância. Oferece cerca de 100 cursos técnicos, 60 cursos de graduação, 10 especializações, 11 mestrados e um doutorado profissional (Ifes, 2021).

\section{Sobre a Aplicação da Lei no 12.990/2014 na Ufes}

Para analisarmos a aplicação da Lei no $12.990 / 2014$ na Ufes, foram consultados todos os editais num recorte de 2014 até o ano de 2020.

$\mathrm{Na}$ análise dos 182 editais da Ufes, foram considerados todos que traziam vagas para professor do magistério superior ou professor de ensino básico, técnico e tecnológico. Para isso, os dados relacionados aos concursos foram divididos em vagas para negros e para ampla concorrência, conforme descrito na Tabela 1.

Ao analisarmos a Tabela 1, primeiramente, o que chama a atenção é a quantidade de editais lançados por ano. Isso se deve à metodologia adotada pela Ufes por meio dos editais $n^{\circ} 97,98$ e 99, publicados em 2014. Para a universidade, a demanda por docentes gerada por departamento resulta em um edital específico. Com isso, as vagas são pulverizadas, e o quantitativo de cada edital não passa de uma ou duas vagas. Sendo assim, não há obrigação de aplicação da Lei no 12.990/2014.

Todavia, o edital no 99, de 5 de dezembro de 2014, disponibilizou três vagas para o Departamento de Engenharias e Tecnologias e, mesmo assim, não teve vagas reservadas para negros. Cabe destacar que a Lei ${ }^{\circ} 12.990$ foi aprovada em 9 de junho de 2014, seis meses antes do certame. 
Tabela 1. Vagas oferecidas em concursos públicos da Universidade Federal do Espírito Santo (Ufes), no período de 2014 a 2020

\begin{tabular}{ccccc} 
Ano & Quantidade de editais & Total de vagas & Vagas para negros & Vagas para ampla concorrência \\
\hline 2014 & 10 & 79 & 0 & 79 \\
\hline 2015 & 9 & 90 & 0 & 90 \\
\hline 2016 & 55 & 83 & 2 & 81 \\
\hline 2017 & 41 & 54 & 0 & 54 \\
\hline 2018 & 27 & 38 & 1 & 37 \\
\hline 2019 & 38 & 48 & 0 & 48 \\
\hline 2020 & 2 & 2 & 0 & 2 \\
\hline Total & 182 & 394 & 3 & 391 \\
\hline
\end{tabular}

Fonte: Elaborada pelos autores.

Até o edital no 90, de 5 de dezembro de 2014, todas as vagas do concurso estavam distribuídas em um único edital, mesmo mantendo a divisão por departamento. Do edital citado, por exemplo, consta o quantitativo de nove vagas, distribuídas entre cinco departamentos diferentes. Se a universidade tivesse aplicado o que preceitua a Lei $\mathrm{n}^{\circ} 12.990 / 2014$, duas vagas deveriam ter sido disponibilizadas para a cota racial, mas não foi isso que ocorreu.

Na Tabela 1 é possível verificar que em sete anos 394 vagas foram disponibilizadas e apenas três foram reservadas para negros, sendo duas vagas em 2016 e uma em 2018.

No ano de 2016, uma das vagas direcionada para as cotas veio por retificação do edital no 53/2016, que a princípio ofertava três vagas de docentes para o Departamento de Engenharia Elétrica, mas sem aplicar a Lei $n^{\circ}$ 12.990/2014. Já a outra vaga de 2016 foi disponibilizada no edital no 34/2016, para o Departamento Teorias do Ensino e Práticas Educacionais.

Em 2018, a única vaga para pretos e pardos consta do edital no 57/2018, direcionado para o Departamento de Pediatria.

Sobre a metodologia adotada pela Ufes em seus concursos públicos, que impede a aplicação da Lei $n^{\circ}$ 12.990/2014, valemo-nos da Ação Declaratória de Constitucionalidade no 41, de 8 de junho de 2017, do relator ministro Roberto Barroso, que apresentou fundamentos sobre a constitucionalidade da lei:

Por fim, a administração pública deve atentar para os seguintes parâmetros:

- Os percentuais de reserva de vaga devem valer para todas as fases dos concursos;

- A reserva deve ser aplicada em todas as vagas oferecidas no concurso público (não apenas no edital de abertura);

- Os concursos não podem fracionar as vagas de acordo com a especialização exigida para burlar a política de ação afirmativa, que só se aplica em concursos com mais de duas vagas; e

- A ordem classificatória obtida a partir da aplicação dos critérios de alternância e proporcionalidade na nomeação dos candidatos aprovados deve produzir efeitos durante toda a carreira funcional do beneficiário da reserva de vagas (STF, 2017).

Assim posto, a Ação Declaratória de Constitucionalidade deixa evidente o critério de aplicação da lei. 


\section{Sobre a Aplicação da Lei no $12.990 / 2014$ no Ifes}

Para o Ifes, foram considerados todos os editais que ofertavam vagas para os cargos de professor do ensino básico, técnico e tecnológico, para atuar na educação profissional de nível médio, técnico e tecnológico e na educação superior, nas modalidades presencial e a distância, conforme descrito na Tabela 2.

Tabela 2. Vagas oferecidas em concursos públicos do Instituto Federal de Educação, Ciência e Tecnologia do Espírito Santo (Ifes), no período de 2014 a 2020

\begin{tabular}{ccccc}
\hline Ano & Quantidade de editais & Total de vagas & Vagas para negros & Vagas para ampla concorrência \\
\hline 2014 & 2 & 99 & 0 & 99 \\
\hline 2015 & 2 & 80 & 20 & 60 \\
\hline 2016 & 2 & 35 & 4 & 31 \\
\hline 2017 & - & - & - & - \\
\hline 2018 & 1 & 24 & 0 & 24 \\
\hline 2019 & - & - & - & - \\
\hline 2020 & - & - & - & - \\
\hline Total & 7 & 238 & 24 & 214 \\
\hline
\end{tabular}

Fonte: Elaborada pelos autores..

Por meio da análise dos sete editais lançados no período, foi possível constatar que a disponibilização das vagas para as cotas raciais se dá conforme o entendimento dos gestores sobre o critério de aplicação dos $20 \%$ no número mínimo de vagas oferecidas no concurso público. Novamente cabe trazer que a Lei $\mathrm{n}^{\circ} 12.990 / 2014$ designa em seu artigo $1^{\circ}$ que a reserva de vagas será aplicada sempre que o número de vagas oferecidas no concurso público for igual ou superior a três (Brasil, 2014).

O texto da lei menciona concurso público, o que nos leva ao entendimento de se tratar da totalidade de vagas do certame, entretanto o Ifes utiliza o critério de divisão das vagas em subáreas para justificar a não aplicação dos 20\%: "Somente haverá reserva imediata de vagas para os candidatos que se autodeclararem pretos ou pardos quando o número de vagas por subárea for igual ou superior a três ou quando o quadro de vagas indicar a existência de vaga prioritária" (Brasil, 2016).

No ano de 2016, foram abertos dois concursos para o provimento de 35 vagas para docente: o edital $\mathrm{n}^{\circ} 2$, de 30 de agosto de 2016, que disponibilizou 11 vagas, sendo duas para negros; e o edital no 3 , de 31 de agosto de 2016, que disponibilizou 24 vagas para professor, sendo apenas duas para negros, quando deveriam ter sido disponíveis cinco, conforme critério de arredondamento previsto na lei.

Ao contrário da Ufes, o Ifes lança apenas um edital contendo todas as vagas disponíveis para seus campi: "O certame destina-se a selecionar candidatos para provimento de 24 vagas para o cargo de Professor do Ensino Básico, Técnico e Tecnológico” (Brasil, 2016). Todavia, como já dito, vale-se do critério de subárea para justificar a divisão das vagas.

Apesar de ter feito referência à Lei no 12.990/2014 - "das vagas destinadas para candidatos pretos ou pardos, em cada subárea e das que vierem a surgir durante o prazo de validade do concurso, 20\% serão providas na forma da Lei no 12.990 , de 9 de junho de 2014" (Brasil, 2016) -, a quantidade de vagas destinadas para os autodeclarados pretos e pardos, no ano de 2016, deveria ser sete, tomando como base a aplicação correta dos $20 \%$ do total de vagas do concurso.

Anteriormente a esse cenário, em fevereiro de 2014, Silva e Silva analisaram o Projeto de Lei $\mathrm{n}^{\circ} 6.738 / 2013$, que posteriormente se tornaria a Lei $\mathrm{n}^{\circ} 12.990 / 2014$, já prevendo a dificuldade na aplicação dos $20 \%$ para a reserva de vagas, nos concursos para docentes: 
Outro ponto de destaque são os concursos com baixo número de vagas, entre os quais o exemplo mais contundente talvez seja o magistério superior. Geralmente, há menos de três vagas para cada cargo, tendo em vista a especialização requerida. Assim, no espaço universitário, embora seja o "nascedouro" das ações afirmativas para negros, a lei não surtirá muito efeito. Desse modo, convêm avaliar este tipo de concurso e outros que congreguem as mesmas características e propor medidas alternativas para ampliação da representação racial em cargos específicos, conjugando, além da reserva de vagas, ações como estratégias de recrutamento voltadas para a população negra habilitada, alteração no formato dos concursos (ampliando o espectro de atuação do cargo, de modo a permitir aglutinação de vagas, quando possível), entre outras táticas inovadoras e mais oportunas que as próprias instituições poderão formular, a exemplo do que ocorreu na criação dos diferentes sistemas de ação afirmativa para discentes (Silva e Silva, 2014, p. 17).

Em 2015, a Seppir divulgou a Nota Técnica no 43/2015, sobre as cotas nos concursos públicos federais, com dados estatísticos que já apontavam a interpretação equivocada da Lei n 12.990/2014 pelas universidades e pelos institutos federais. Na nota, a Seppir deixa claro que as vagas reservadas devem ser proporcionais ao total destinado ao concurso público (Brasil, 2015).

Para resolver essa questão, o Instituto Federal de Educação, Ciência e Tecnologia do Maranhão adotou a metodologia de sorteio como critério na definição das vagas a serem destinadas à reserva para negros, conforme podemos constatar no edital de concurso público n 1 , de 21 de setembro de 2018: "As vagas destinadas a candidatos negros serão definidas por meio de sorteio público a ser realizado no dia 2 de outubro de 2018, às 10 h no auditório da Reitoria" (Brasil, 2018). A instituição aplica o que recomendou a Seppir e o que está descrito na Lei no 12.990/2014:

As vagas reservadas a candidatos negros devem ser distribuídas com base no quantitativo total de vagas até o atendimento do percentual disposto no item 5.2.1, independente da área, uma vez que a definição do cargo de Professor do Ensino Básico, Técnico e Tecnológico não apresenta distinção de área/subárea, conforme o disposto no item 3.2 deste edital (BRASIL, 2018).

A Universidade Federal de Minas Gerais, no edital no 664, de 20 de setembro de 2019, que trata de concurso público de provas e títulos para provimento efetivo da carreira de magistério superior, também adotou o sorteio como critério para identificação da área de conhecimento a ser destinada às cotas raciais: "As vagas reservadas foram destinadas por meio de realização de sorteio em sessão pública pela Diretoria da Unidade Acadêmica responsável pelo concurso" (Brasil, 2019).

Outro exemplo de aplicação da Lei no 12.990/2014 conforme o que está descrito em seu artigo $1^{\circ}$ é o edital $\mathrm{n}^{\circ}$ 006, de 16 de janeiro de 2020, da Universidade Federal de Santa Maria: "De acordo com o disposto na Lei $\mathrm{n}^{\circ}$ 12.990/2014, fica assegurada a reserva de vagas aos candidatos negros (pretos e pardos) em $20 \%$ (vinte por cento) do número total de vagas deste Edital" (Brasil, 2020). Nesse edital, foram ofertadas três vagas para áreas diferentes, uma vaga para a área de engenharia elétrica e duas para ciências da saúde. Mesmo assim, uma vaga foi reservada para os candidatos negros, como prevê a interpretação indicada pela Seppir. Nesse sentido, a universidade utilizou o seguinte critério:

A ocupação das vagas dar-se-á de tal modo que o primeiro classificado na listagem específica de candidatos negros neste concurso será convocado para ocupar a $3^{\mathrm{a}}$ vaga do Edital. Os demais candidatos negros aprovados serão convocados para ocupar a $8^{\mathrm{a}}$, a 13 a a 18 a a $23^{\mathrm{a}}$ vaga e assim sucessivamente, quando houver mais vagas a serem preenchidas, dentro do prazo de validade do concurso (Brasil, 2020). 
É oportuno ponderar que possivelmente as autarquias, as fundações públicas, as empresas públicas e as sociedades de economia mista controladas pela União que aplicam outro entendimento sobre a reserva de vagas para os negros se valem do descrito por Oliveira e Targino (2017), ao analisarem as inconsistências da Lei $n^{\circ} 12.990 / 2014$ : “O $\$ 1^{\circ}$, ao ser aplicado, perfaz um percentual de 33,33\% de reserva de vagas, ou seja, superior ao próprio caput do art. 1º, qual seja, 20\%” (Oliveira e Targino, 2017, p. 381).

Nessa interpretação, num universo de três vagas, correspondente a 100\%, cada vaga equivale a $33,33 \%$, desobrigando a aplicação da lei. Além disso, para os autores, a referida lei é imprecisa e lacunosa e pode até gerar mais segregação racial, em função de sua insegurança jurídica.

\section{Considerações Finais}

Ao analisarmos a aplicação da Lei no 12.990/2014, no âmbito dos concursos públicos para docentes, nas instituições federais de ensino do Espírito Santo, foi possível constatar equívocos em sua aplicação.

Ao mapearmos 182 editais da Ufes e sete do Ifes, lançados num período de sete anos, podemos perceber a força do racismo em nossas instituições públicas, pois as artimanhas para driblar o que está posto legalmente estão logrando êxito. Apesar dos sete anos de vigência, nas instituições pesquisadas, a lei não cumpre o objetivo de corrigir os efeitos da discriminação racial, ao assegurar a igualdade de oportunidades e possibilitar a inclusão de mais negros no serviço público.

Outro ponto constatado pela pesquisa foi a falta de relatórios do Executivo Federal sobre os dados do monitoramento constante da aplicação da Lei no 12.990/2014 e verificação da sua eficácia, como dispõe a própria lei e o Estatuto da Igualdade Racial.

Nesse contexto, torna-se urgente o estabelecimento de procedimentos padrão a serem adotados pelos gestores públicos federais em relação à aplicação do percentual de $20 \%$ das vagas oferecidas nos concursos públicos. Considerando como a Lei no 12.990/2014 é aplicada no Espírito Santo, é inegável que ela apresenta brechas em seu texto que possibilitam diferentes interpretações dos gestores.

Da mesma forma, é evidente que o Brasil levará décadas para que a proporção de docentes negros nas instituições públicas federais se equipare ao percentual de docentes brancos. A representatividade está a passos lentos, enquanto a Lei $n^{\circ} 12.990 / 2014$ tem seu prazo de vigência até 2024. Ao nosso ver, além da necessidade de mudança no texto da Lei no $12.990 / 2014$, faz-se iminente a prorrogação do seu prazo de vigência para que os resultados sejam positivos.

Sendo assim, pode-se entender que o objetivo deste artigo foi cumprido. Para pesquisas futuras, sugere-se analisar o papel dos Núcleos de Estudos Afro-Brasileiros e Indígenas das universidades e dos institutos federais, perante essa demanda.

\section{Contribuições dos Autores}

Problematização e conceituação: Fernandes RRD e Santos VS; Metodologia: Dias RR; Análise: Jacob A; Redação: Fernandes RRDs e Santos VS 


\section{Referências}

ALMEIDA, S. L. Racismo estrutural. São Paulo: Sueli Carneiro, Pólen, 2019.

ALMEIDA, S. L. Capitalismo e crise: o que o racismo tem a ver com isso? Democracia e Mundo do Trabalho em Debate, 2 jul. 2020. Disponível em: https://www.dmtemdebate.com.br/capitalismo-e-crise-o-que-oracismo-tem-a-ver-com-isso/. Acesso em: 10 abr. 2021.

BRASIL. Lei no 10.639, de 9 de janeiro de 2003. Altera a Lei $\mathrm{n}^{\circ}$ 9.394, de 20 de dezembro de 1996, que estabelece as diretrizes e bases da educação nacional, para incluir no currículo oficial da Rede de Ensino a obrigatoriedade da temática "História e Cultura Afro-Brasileira" [...]. Brasília: Senado Federal, 2003. Disponível em: https://www.planalto.gov.br/ccivil_03/leis/2003/110.639.htm. Acesso em: 13 mar. 2021.

BRASIL. Lei no 12.288, de 20 de julho de 2010. Institui o Estatuto da Igualdade Racial [...]. Brasília: Senado Federal, 2010. Disponível em: http://www.planalto.gov.br/ccivil_03/_ato2007-2010/2010/lei/112288.htm. Acesso em: 13 mar. 2021.

BRASIL. Lei no 12.711, de 29 de agosto de 2012. Dispõe sobre o ingresso nas universidades federais e nas instituições federais de ensino técnico de nível médio [...]. Brasília: Senado Federal, 2012. Disponível em: http://www.planalto.gov.br/ccivil_03/_ato2011-2014/2012/lei/112711.htm. Acesso em: 13 mar. 2021.

BRASIL. Lei no 12.990, de 9 de junho de 2014. Reserva aos negros $20 \%$ (vinte por cento) das vagas oferecidas nos concursos públicos para provimento de cargos efetivos e empregos públicos no âmbito da administração pública federal, das autarquias, das fundações públicas, das empresas públicas e das sociedades de economia mista controladas pela União. Brasília: Senado Federal, 2014. Disponível em: http://www.planalto.gov.br/ ccivil_03/_ato2011-2014/2014/lei/112990.htm. Acesso em: 13 mar. 2021.

BRASIL. Nota Técnica no 43/2015 - SPAA/Seppir/PR. Brasília: Seppir, 2015. Disponível em: https://direito. mppr.mp.br/arquivos/File/manifestacaoseppir.pdf. Acesso em: 10 jun. 2021.

BRASIL. Edital no 03, de 31 de agosto de 2016. Institui o concurso público de provas e títulos para professor do Ensino Básico, Técnico e Tecnológico do Instituto Federal do Espírito Santo. Brasil, 2016. Disponível em: https://www.ifes.edu.br/processosseletivos/servidores/item/2100-concurso-publico-03-2016-docentesmestres-e-doutores. Acesso em: 10 jun. 2021.

BRASIL. Edital no 1, de 21 de setembro de 2018, institui o concurso público para docentes do magistério superior do Instituto Federal do Maranhão. Diário Oficial da União, Brasília, Edição 184, Seção 3, p. 81, 2018.

BRASIL. Edital no 185, de 24 de setembro de 2019. Institui o concurso público para docentes do magistério superior da Universidade Federal de Minas Gerais. Diário Oficial da União, Brasília, Edição 81, Seção 3, p. 72-75, 2019.

BRASIL. Edital no 006, de 16 de janeiro de 2020. Concurso Público destinado ao provimento de cargos da carreira de magistério superior da Universidade Federal de Santa Maria. Diário Oficial da União, Brasília, Edição 13, Seção 3, p. 207, 2020.

FERNANDES, O. As cores da desigualdade. [Entrevista concedida a] Irene Gomes e Mônica Marl. Retratos à Revista do IBGE, p. 15-19, maio 2018. Disponível em: https://agenciadenoticias.ibge.gov.br/media/com_ mediaibge/arquivos/17eac9b7a875c68c1b2d1a98c80414c9.pdf. Acesso em: 2 abr. 2021. 
GOMES, N. L. Alguns termos e conceitos presentes no debate sobre relações raciais no Brasil: uma breve discussão. In: BRASIL (org.). Educação anti-racista: caminhos abertos pela Lei federal no 10.639/03. Brasília: MEC, 2005. Disponível em: http://etnicoracial.mec.gov.br/publicacoes/item/9-educacao-anti-racistacaminhos-abertos-pela-lei-federal-n-10-63903. Acesso em: 2 abr. 2021.

INSTITUTO BRASILEIRO DE GEOGRAFIA E ESTATÍSTICA [IBGE]. Pesquisa Nacional por Amostra de Domicílios Contínua (PNAD Contínua). IBGE, 2018. Disponível em: https://educa.ibge.gov.br/jovens/ conheca-o-brasil/populacao/18319-cor-ou-raca.html. Acesso em: 30 mar. 2021.

INSTITUTO FEDERAL DE EDUCAÇÃO, CIÊNCIA E TECNOLOGIA DO ESPÍRITO SANTO [IFES]. Institucional. Página inicial. Espírito Santo: Ifes. Disponível em: https://www.ifes.edu.br/o-ifes. Acesso em: 10 abr. 2021.

INSTITUTO NACIONAL DE ESTUDOS E PESQUISAS EDUCACIONAIS ANÍSIO TEIXEIRA [INEP]. Censo da Educação Superior 2018: notas estatísticas. Brasília: Inep, 2019. Disponível em: https://download. inep.gov.br/educacao_superior/censo_superior/documentos/2019/censo_da_educacao_superior_2018notas_estatisticas.pdf. Acesso em: 10 abr. 2021.

JACCOUD, L. B.; BEGHIN, N. Desigualdades raciais no Brasil: um balanço da intervenção governamental. Brasília: Ipea, 2002.

MELLO, L.; RESENDE, U. P. Concursos públicos para docentes de universidades federais na perspectiva da Lei 12.990/2014: desafios à reserva de vagas para candidatas/os negras/os. Sociedade e Estado, v. 34, n. 1, 2019. Disponível em: https://www.scielo.br/j/se/a/FxSgTjKCPwjckjYxwX5jR9g/abstract/?lang=pt. Acesso em: 11 jun. 2021.

MOORE, C. Racismo e sociedade: novas bases epistemológicas para entender o racismo. Belo Horizonte: Mazza Edições, 2007.

MUNANGA, K. Uma abordagem conceitual das noções de raça, racismo, identidade e etnia. Inclusão Social, 2017. Disponível em: https://www.ufmg.br/inclusaosocial/?p=59. Acesso em: 11 jun. 2021.

NASCIMENTO, A. Ação afirmativa: o debate como vitória. Inclusão Social: um debate necessário? Belo Horizonte: UFMG, 7 jul. 2006. Disponível em: https://www.ufmg.br/inclusaosocial/?p=62. Acesso em: 20 jun. 2021.

OLIVEIRA, E. A. R.; TARGINO, M. F. S. Cotas no serviço público federal: lei 12.990/2014 e o sistema autodeclaratório: lacunas legislativas e antinomias em relação ao sistema jurídico brasileiro. Holos, v. 1, p. 374-85, jul. 2017. https://doi.org/10.15628/holos.2017.5073

ORGANIZAÇÃO DAS NAÇÕES UNIDAS [ONU]. Declaração e Plano de Ação da III Conferência Mundial de Combate ao Racismo, Discriminação Racial, Xenofobia e Intolerância Correlata. Brasília: Fundação Cultural Palmares, 2001. Disponível em: http://www.unfpa.org.br/Arquivos/declaracao_durban.pdf. Acesso em: 20 mar. 2021.

PALMA, V. C. L. C. F. Educação, democracia e inclusão racial: análise da efetividade da lei de cotas para negros em concursos docentes de universidades federais. 2019. 334fls. Tese (Doutorado em Educação) - Universidade Federal da Grande Dourados, Dourados, 2019. Disponível em: https://repositorio.ufgd.edu.br/jspui/bitstream/ prefix/1136/1/VanessaCristinaLourencoCasottiFerreiradaPalma.pdf. Acesso em: 20 mar. 2021.

SILVA, M. A. B. Racismo institucional: pontos para reflexão. Laplage em Revista, São Carlos, v. 3, n. 1, 2017. https://doi.org/10.24115/S2446-6220201731223p.127-136 
SILVA, T. D.; SILVA, J. M. Nota Técnica no 17: Reserva de vagas para negros em concursos públicos: uma análise a partir do Projeto de Lei 6.738/2013. Brasília: Ipea, 2014. Disponível em: http://repositorio.ipea.gov. br/bitstream/11058/5781/1/NT_n17_Reserva-vagas-negros-concursos-publicos_Disoc_2014-fev.pdf. Acesso em: 10 abr. 2021.

SUPREMO TRIBUNAL FEDERAL (STF). Ação Declaratória de Constitucionalidade no 41-DF. Plenário. Relator: Ministro Roberto Barroso. Brasília: DJe, 2017. Disponível em: https://redir.stf.jus.br/paginadorpub/ paginador.jsp?docTP=TP\&docID=13375729. Acesso em: 11 abr. 2021.

UNIVERSIDADE FEDERAL DO ESPÍRITO SANTO (UFES). A instituição. Página inicial. Vitória: Ufes. Disponível em: https://www.ufes.br/institui\%C3\%A7\%C3\%A3o. Acesso em: 10 abr. 2021.

WERNECK, J. Racismo institucional: uma abordagem conceitual. São Paulo: Geledés, 2013. Disponível em: https://bibliotecadigital.mdh.gov.br/jspui/bitstream/192/381/1/GELED\%C3\%89S_Racismo.pdf. Acesso em: 13 mar. 2021.

\section{Sobre os Autores}

Rosane Rosa Dias Fernandes é bacharel em Contabilidade pela Faculdades Integradas Castelo Branco, com Complementação Pedagógica em Matemática pela Universidade Metropolitana de Santos e mestre em Educação pela Universidade Federal do Espírito Santo. Tem interesse nas áreas de educação, educação a distância, educação para as relações étnico-raciais e racismo.

Victor Silva Santos é bacharel em Direito pela Faculdade Novo Milênio e pós-graduado em Administração Pública pelo Instituto Federal de Educação, Ciência e Tecnologia do Espírito Santo (Ifes) Campus Colatina. Tem interesse nas áreas de direito, administração pública e racismo.

AleXANDRE JACOB é bacharel em Direito pelo Centro Universitário do Espírito Santo, especialista em História e Cultura Afro-Brasileira e Indígena pelo Centro Universitário Internacional e mestre em Ciências das Religiões pela Faculdade Unida de Vitória. Tem interesse nas áreas de direito, educação e gestão, com ênfase em ciências criminais, educação profissional e tecnológica, educação a distância, gestão pública, direitos humanos, religiões de matriz africana e educação para as relações étnico-raciais.

Rany Rosa Dias é graduada em Saneamento Ambiental e pós-graduada lato sensu em Gestão Pública, ambas pelo Instituto Federal de Educação, Ciência e Tecnologia do Espírito Santo, campus Colatina. Atua como membro do Núcleo de Estudos Afro-Brasileiros e Indígenas do campus Itapina. Tem interesse nas áreas de gestão pública, educação, educação para as relações étnico-raciais e racismo.

Recebido: 30 jul. 2021

Aceito: 26 out. 2021 